\title{
(息)
}

Citation:

Hanna, ES and Gough, B and Hudson, N (2018) Fit to father? Online accounts of lifestyle changes and help-seeking on a male infertility board. Sociology of Health and IIIness, 40 (6). pp. 937-953. ISSN 1467-9566 DOI: https://doi.org/10.1111/1467-9566.12733

Link to Leeds Beckett Repository record:

https://eprints.leedsbeckett.ac.uk/id/eprint/4617/

Document Version:

Article (Accepted Version)

The aim of the Leeds Beckett Repository is to provide open access to our research, as required by funder policies and permitted by publishers and copyright law.

The Leeds Beckett repository holds a wide range of publications, each of which has been checked for copyright and the relevant embargo period has been applied by the Research Services team.

We operate on a standard take-down policy. If you are the author or publisher of an output and you would like it removed from the repository, please contact us and we will investigate on a case-by-case basis.

Each thesis in the repository has been cleared where necessary by the author for third party copyright. If you would like a thesis to be removed from the repository or believe there is an issue with copyright, please contact us on openaccess@leedsbeckett.ac.uk and we will investigate on a case-by-case basis. 


\section{Fit to father? Online accounts of lifestyle changes and help-seeking on a male infertility board}

Abstract: The reproductive realm is routinely viewed as a feminised space requiring women's commitment and labour. By contrast, men's procreative contributions and 'reproductive masculinity' is represented as unproblematic, with men assumed to be fertile across the lifespan. Recent scientific research has, however, cast doubt over these longstanding assumptions, suggesting that a link does exist between 'lifestyle' factors and male fertility. The notion that fertility can be improved with effort (for both women and men) can be located within wider cultural and political shifts which construct individuals as increasingly responsible for acting on health messages and engaging in self-disciplining body projects. Through an exploration of 'lifestyle changes' within a men's online infertility discussion forum board, this paper examines how discourses of individualisation healthism and masculinity are reproduced and interlinked. Our thematic analysis indicates that 'lifestyle work' is construed as crucial for achieving conception - and as a means to demonstrate men's commitment to the dyadic goal of parenthood, which in turn may challenge and extend previous notions of 'reproductive masculinity'.

Keywords: Lifestyle, Infertility, Men, Reproduction, healthism

\section{Introduction}

The reproductive realm is routinely viewed as a feminised space requiring women's attention, commitment and labour. Although men have been integrated as health consumers for some time (c.f. Gough \& Robertson, 2009; Robertson, 2007), and hegemonic masculinity is increasingly associated with 'clean' lifestyle choices, men's accounts of health-related practices in relation to fertility have not been given any systematic sociological consideration. 'Reproductive masculinity' (Daniels, 2006) positions men as being secondary in reproduction, less vulnerable to reproductive harm, virile and distant from the health problems of children. As a result, and in contrast to those of women, men's procreative contributions are often ignored, left unproblematised or characterised 
with reference to norms singularly linking masculinity to fertility and potency (Daniels, 2006; Almeling and Waggoner, 2013; Barnes, 2014; AUTHOR 3; Lohan, 2015;). A long-standing political and scholarly silence surrounding men's reproductive masculinity has been compounded in recent times by an evergreater focus on women's health and lifestyle before and during pregnancy (Lee, 2014). So-called 'lifestyle' factors, such as alcohol consumption, diet, weight and smoking, are increasingly policed in relation to pregnancy, and the notion of women being 'fit' for pregnancy and motherhood is appearing on public health agendas, with professionals directly encouraging those who are considered 'unhealthy' to delay conception whilst improving their health status (Sher, 2016). By contrast, portrayals of men's apparent ability to reproduce across the lifespan, regardless of age and lifestyle, are well-established and have remained culturally pervasive. These are apparent in the high-profile media reporting of celebrity older fathers ${ }^{1}$. The impact of lifestyle on men's reproductive outcomes and their fitness to procreate has hitherto been missing from public discourse.

Recent scientific research and dialogue has, however, cast doubt over these longstanding assumptions, suggesting instead that a link does exist between 'lifestyle' factors and male fertility (Sharpe, 2000). These studies present lifestyle as a contemporary set of 'risks' that need to be managed, and suggest that such risks are increasing (Axelsson, Bonde, Giwercman, Rylander and Giwercman, 2010; Jurewicz, Radwan, Sobala, Ligocka, Radwan, Bochenek and Hanke, 2015; Rato, Alves, Cavaco and Oliveria, 2014). Recent media coverage has constituted somewhat of a 'moral panic' around rapidly declining sperm counts in the Western world ${ }^{2}$. These developments potentially challenge a core idea within Daniels' conceptualisation of reproductive masculinity i.e. that men and male fertility are less vulnerable to reproductive harm than women and female fertility (Daniels 2006).

\footnotetext{
${ }^{1}$ For example see recent reporting of Ronnie Woods fathering of twins at age 68 http://www.bbc.co.uk/news/entertainment-arts-36415915

${ }^{2}$ For example of coverage of reports that sperm counts are declining see: https://www.theguardian.com/science/2017/jul/29/infertility-crisis-sperm-counts-halved or http://www.telegraph.co.uk/news/2017/07/25/alarm-modern-life-sees-average-sperm-count-halve-since1970s/
} 
Such studies and the corresponding media coverage suggest that male fertility is in fact compromised by factors such as smoking, alcohol use and stress (Fertility Weekly, Jan 2015), as well as caffeine consumption, obesity and diet (Jurewicz et al., 2015; Rato et al., 2014; Wright, Milne and Leeson et al., 2014) and mobile phone use (Zilberlicht, Wiener-Megnazi, Sheinfield, Grach, Lahav-Baratz and Dirnfeld, 2015). Increased paternal age has also recently been suggested as a risk factor for fertility problems - a pattern that may be set to increase given wider social trends in Western societies relating to later childbearing (Karavalos, Stewart, Evbuomwan, McEleny and Aird, 2013; Ausmees, Mandar, Korrovits, Zarkovski, Timberg and Punab, 2014). This body of work contradicts previous thinking which construed male fertility (and corresponding ideas about reproductive masculinity) as constant across the lifecourse, while female fertility has long been regardedas vulnerable to processes of ageing and decline (especially after age 35), dominated by the'biological clock' metaphor.

As a consequence of the identification of a range of risk factors for men, corresponding behaviour changes (for example reducing alcohol intake, smoking and healthy eating) are being suggested as a means to improve semen quality (Karavalos et al., 2013; Rato et al., 2014). National Institute for Health and Care Excellence (NICE) guidance in the UK suggests that men who are trying to conceive should avoid 'excessive alcohol intake' (NICE, 2013:8), that men with a BMI of over 30 are likely to have reduced fertility, and that smoking can reduce semen quality (NICE, 2013). Some scientists go further than this, suggesting that 'male partners of infertile couples should strictly abstain from alcohol consumption and cigarette smoking' (Gaur, Talekar and Pathak, 2010: 40), and that dietary vitamin supplements should be taken (Wright et al., 2014). The use of mobile telephones is also presented as a risk to their potential fertility and men are advised to change or reduce their use of this technology (Zilberlicht et al., 2015: 425).

Almeling and Waggoner have argued that a historical absence of scientific evidence about the role of men and sperm in reproductive outcomes is a symptom of the invisibility of men in the reproductive realm per se (Almeling and Waggoner, 2013). The idea that fertility can be improved with effort (for 
both women and men) can also be located within wider cultural and political shifts which see individuals as increasingly responsible for acting on health messages and engaging in body projects. These messages may in turn provide a possible challenge to prevailing notions of reproductive masculinity, which has historically presented male fertility as a relatively stable phenomenon less vulnerable to harm than female fertility (Daniels, 2006). The individualisation of patients, whereby individuals are instilled with a moral imperative to do everything possible to improve their health, is part of the wider neo-liberal landscape in which citizens are redefined as individualised, self-governing consumers (Dent, 2006). In the case of infertility, for example, there is a growing marketization of a range of fertility treatment options - part of what has been referred to as the 'fertility-industrialcomplex' (Spar, 2006).

In this paper, we consider how these emerging discourses related to the malleability of male fertility, as presented in scientific studies and the media discourse surrounding them, are discussed online by men and women who are experiencing infertility. Lifestyle work by men in relation to fertility may have been occurring for some time, but it has not yet been subject to a sociological gaze, and in the context of ever-increasing healthism, lifestylisation and restrictions on fertility treatment, it is timely to explore this topic. We do so through an examination of 'lifestyle changes' within one online infertility discussion forum board, we explore how men and women navigate ideas of lifestyle modifications for men as part of their wider 'conception projects'. The paper seeks to highlight some of the ways in which contributors to the board positioned themselves (and in the case of female contributors, their partners) and their practices in relation to discourses of lifestyle and individual body projects. We will also explore how our findings extend or contest a conceptualisation of 'reproductive masculinity', which sees male fertility as vital, robust and fixed, within this context. By illuminating the dominant discourses and subject positions pertaining to male in/fertility present in this example, this approach offers wider potential for reducing the focus on women in relation to fertility, and facilitating debates and practices which are more gender-inclusive and egalitarian. 


\section{Methodology}

In order to access men's accounts, we examined an online discussion board designed for men located within a UK-based infertility forum. We searched for a relevant board using the keywords 'infertility forum + men' and we discounted those forums attached to clinics as well as those hosted within often heavily feminised sites (i.e. where the word 'mum' or similar appears within the title). The board we focus on is advertised as being for men to 'talk' with one another, and the context is around infertility as a whole, not specifically male-factor infertility (other sites which offer space for male-factor discussion also exist), and was chosen prior to examining the posts within the men's board, i.e. we screened for a forum, then moved to screening for posts. Whilst the board is advertised as a space for men, assessment of contributor names and gender tags on profiles shows that the board appears to feature a number of posts by women, thus enabling us to gain insight into relevant gendered positions and dynamics which builds on existing research into men's online accounts of infertility (Hanna and Gough, 2016a and b). As we have discussed elsewhere (Hanna and Gough, 2016 a and b), such online spaces enable social scientists to examine how a 'community of practice' (Paetcher, 2004) supports members and offers advice beyond the confines of professional or formalised settings.

The forum is open, does not require a login for access, attracts high traffic, and is freely available in the public domain. The research followed established ethical procedures and practices (e.g. British Sociological Association statement of ethical practice ${ }^{3}$ ), and ethical approval was gained from the university ethics committee (Reference: 26499). We did not engage with the forum (i.e. post on it ourselves) and, following the now established approaches for forum analysis (Stommel \& Koole, 2010), conducted data collection at a specific point in time and screened retrospectively. Usernames of contributors and other potentially identifying information has been anonymised, and numbers attributed to contributors in order to differentiate between them (e.g. P [Poster) number; $M$ or F [for

\footnotetext{
${ }^{3}$ https://www.britsoc.co.uk/equality-diversity/statement-of-ethical-practice/
} 
sex); the sex of contributors has also been noted, identified via usernames on the forum and other sex-related features such as references to wife/girlfriend, boyfriend/husband.

Having selected a forum we then began to screen for data pertinent to our research question. The content within the forum was initially read for relevant threads, using thread titles as an indicator of content, such as those signalling advice seeking or using lifestyle related words (e.g. diet, alcohol, exercise). The posts were included from the first five pages of the board and covered a period of three years. This time period was chosen so as to ensure the data were contemporary given the changing nature of lifestyle advice over time. The forum contained a mix of threads and posts relating to various other aspects of men's experiences of infertility, such as around the emotions of infertility and aspects relating to specific fertility treatment processes; however, given our original question and the lack of evidence around how men do lifestyle work in the context of infertility, screening for threads (and then posts) around lifestyle, and exclusion of others outside this topic, was required in order to create a dataset which was both relevant and manageable. The identified threads were then screened and included within the dataset based on the basis of relevance to our research question: 'what advice or support is sought on a men's board online in relation to lifestyle aspects when experiencing fertility issues'. In total, 107 posts were included in the dataset, sourced from 17 threads involving 35 unique contributors. This fits with the qualitative ethos for online data of this nature where richness and depth is prioritised over quantity of posts (Stommel and Koole, 2010). The data examined relate to the accounts of contributors to one particular forum and are therefore not representative of all online forums. As is the goal of all qualitative research, our aim is to generate theoretical inferences rather than empirical generalisations (Williams, 2000).

The data were analysed thematically using the approach detailed by Braun and Clarke (2006), with the lead researcher [initials to be added to final manuscript] conducting the initial coding and analysis and the research team then meeting to discuss the codes and agreeing upon the broader themes. We frame our research as psychosocial and constructionist, and use this position to inform considerations 
about what is posted, how posts are presented and how social dynamics and structures (e.g. gender norms) are articulated via individual accounts. Four core themes were identified from the analysis and are presented below: Seeking and providing expert peer support; the allure of vitamins; fitness to father; men's commitment to lifestyle changes.

\section{Findings}

\section{Seeking and providing expert peer support}

The forum was used to seek advice and support around a variety of lifestyle aspects, and gendered dynamics around such help seeking (such as women replying to men's posts) were often evident in the data. Many men on the forum sought advice about improving fertility in general terms, but also about specific accommodations such as alcohol consumption and diet:

anyone recommend anything else that may help pill wise? (P6M- Poster 6 Male)

I would like to ask people here what they have done to improve sperm quality etc (P4M)

Just wanted some advice from other's who are going through a similar process, even guys who have been through it and noticed a positive/ negative impact of changes to diet and exercise. (P17M)

$\mathrm{Hi}$, a quick question, does anyone know if bicycle cycling can effect sperm count? (P34M)

Despite some posters, such as Poster 17, asking for advice "from others...guys who have been through it", women also utilised the board to ask about lifestyle aspects in relation to their husbands or partners:

Can any men or ladies offer some advice on TTC [Trying To Conceive] and drinking alcohol? (P1F) 
...my husband really doesn't believe in alternative therapies and is refusing to consider it at the moment...I am hoping that if I can find an independent source he may reconsider his stance (P2F)

The forum was therefore treated as a source of information and advice. Some posters suggested that they had sought out the forum to try and navigate the complexity of information around lifestyle and fertility that exists online.

Reading literature can drive you insane with some articles saying you should literally give up everything, live in a cave, eat organic and follow a very strict regime (P17M)

I have done some research...I was just wondering if anybody has any more advice from personal experience and success (P18M)

It is recognised that information seeking is a priority for those experiencing a fertility issue (Porter and Bhattacharya, 2008), and in light of complex and competing evidence, seeking out testimony based on lived experience was valued. Most changes were perceived to be 'low risk' strategies by men, with contributors encouraging peers by highlighting improvements to general wellbeing at the very least, and to fertility health at best:

It cant do no harm (P7M)

Still, my thoughts are, if you're willing to give it a shot and might help, why not? It can only do $\operatorname{good}(P 13 M)$

I get why some guys may think it's [acupuncture] a weird thing to try (doesn't seem manly or whatever), but if it works, why not try? (P32M)

The reference here to lifestyle change as 'unmanly' may be related to a perception that 'alternative' approaches to health are considered to be feminised and thus men are keen to distance themselves from such positions whilst still remaining open to the importance of the wider conception project and 
the low risk nature of lifestyle adaptions to both their physical self and gender identity. Women posting on the board often expressed enthusiasm about the benefits of various lifestyle accommodations, moving beyond the men's more minimal aspirations of 'doing no harm':

Lifestyle changes can make [a] huge impact. If you drink consider cutting right back. Smoking is also not recommended. Cut coffee back to one per day and the[n] consider supplements (P5F)

Losing the weight will definitely help (P12F- Italics, posters own)

Such assertions emphasise benefits and display certainty around lifestyle factors. Women also shared success stories about their partner's regimes on the board:

I know this area is meant to be for men only, but I wanted to share my husband's experience. When we had our consultation at our private clinic and he did his SA [Semen Analysis], the results were borderline...The day after the consultation he started on Wellman Conception...Anyway, long story short, his sample on egg collection day was amazing...Obviously we will never know if the vitamins played a part, but I strongly suspect they did. In addition to the vitamins, he also hardly drunk any alcohol (P12F)

The narrative bears a typical before-and-after story structure, which contrasts a former ('borderline') situation with the current ('amazing') outcome as a result of intervention. This female contributor justifies her post on a men's forum by foregrounding her husband's experience and offering hope to other men. Relatively few men offered similar 'success' narratives in this way, although women received no criticism for their posting of such narratives on the board, potentially demonstrating the inclusiveness of the forum as a source of help-seeking, advice and story sharing. The main feature that seemed to be valued on the board was securing experience-based insider advice from those who understood the challenges of attempting to conceive in the context of infertility. As health risks become increasingly focused on individual responsibility through discourses of healthism - whereby 
an individual's health is viewed as the primary goal of wellbeing and is achieved through lifestyle modification and adaptation (Crawford, 1980) - it is interesting to note that in this context posters drew on shared and collective experiences to help negotiate their own lifestyle changes. In contrast to traditional disocurses, male fertility was presented as something which could be vulnerable to harm and thus in need of improvement via recourse to shared experiences.

\section{The allure of vitamins}

The topic of vitamins came up frequently on the boards, with many requests for information focusing on advice about selecting a particular supplement. Subsequent discussion revolved around the best brands to use, the correct dosage, and concerns about taking too many vitamins. Although general lifestyle factors such as diet, exercise and alcohol consumption were discussed, there was more interest in vitamin and supplement choices and related advice. Various branded conception multivitamins for men were referenced on the forum:

I have been taking fertilaid over the past 2 months and have now moved on to androferti but have seen a lot of good results from people using wellman, I'm kind of losing faith with it all now as I just seem to be getting nowhere with it (P25M)

Knowing whether fertility has improved following vitamin intake relies on semen analysis and/or conception occurring, thus in the interim period between testing/treatment or successful conception, men lack any tangible, embodied markers of improvement. Nonetheless, many men on the forum seemed to invest heavily in their own vitamin regimes:

I dunno if I've gone a bit nutty here with the vitamins but here goes, I'm currently taking wellman conception, zinc, vit D, vit A,C, E and selenium, omega 3, 6, 9, Korean ginseng and wellman conception for him (P6M)

There was clearly a concern, and some degree of uncertainty expressed, about the number of supplements to be taken. By discussing a range of supplement regimes, the forum community enabled 
comparisons and discussions about the most effective practices, thus helping to address doubt articulated by some of the men. In particular, 'good news' stories functioned to reassure, motivate or demonstrate positive impact to others on the forum:

As it was 3 months before our cycle he started taking wellman vitamins (other brands just as good no doubt), cut out all caffeine and alcohol, ate lots of veg, exercised regularly, wore baggy pants, and took regular breaks from sitting down to do lunges around the office...Three months later his count was $140 \mathrm{mn}$ with excellent motility and morphology.... Impossible to say what this was down to but the vitamins can only have helped. We were expecting maybe a 10-20\% increase but the difference was phenomenal (P19F)

So, despite a myriad of major lifestyle changes, Poster 19 attributes her husband's dramatic improvement in sperm quality/quantity (up from $35 \mathrm{mn}$ to $140 \mathrm{mn}$ ) to the use of vitamins; this post was followed by a reply from a male poster highlighting similar improvements in sperm quantity/quality after using vitamins. On other threads men also provided success narratives around using vitamins, sometimes using these to counter more sceptical views about the impact of vitamins:

I had 2 low sperm counts then got on the supplements and they quadrupled in 12 months (P35M)

Such displays of insider expertise on the forum were sometimes formulated as more direct, authoritative pronouncements:

All men should be taking $2000 \mathrm{mg}$ of vitamin c per pay, it has a massive impact on your sperm but takes 3 months to get right in, also take Wellman conception only available in [name of chemist], it will make your sperm great or even greater (P20M)

Here the advice is specific, with major results emphasised ('massive') and generalised ('all men'); this post is left unchallenged with no other responses. Despite some posters claiming vitamin use as 'straightforward', however, other contributors shared concerns about ingesting too many vitamins: 
Careful you're not taking too much zinc and selenium with Wellman conception and separate vits (P8F)

My hubby just took the Wellman Multivitamins, I was worried that if he took a few separate ones, he'd maybe overdose and thereby could have a negative impact over extended use (P26F)

Men appeared thankful for the responses to their advice seeking ('ta for replies': P6M) and response posts included many lists of 'vitamin' regimes that men (or posters' male partners) were using. When it came to queries about vitamins, many responses and personal experiences were shared. These included some negative stories about the utility of vitamins, here relating to professional advice:

My husband has been diagnosed with low sperm count of 9 million. When I asked the consultant how we can make it a normal amount again ( 20 million) he said that once you are diagnosed with a low sperm count that's it, he said taking no amount of vitamins or doing ex amount of exercise will bring a sperm count up by 11 million to make it a normal result (P21F)

In a later thread the same contributor reported using vitamins despite this medical advice, underlining the perceived power of vitamins within this community. This belief in vitamins is vividly illustrated here:

Wife very downhearted this month cos its first time with all the pills, and pre seed and peeing on an ovulation stick, guess we hoped they were magic (P6M)

As we have noted elsewhere (Hanna and Gough 2016a), infertility experiences can be fraught, creating distress, and the hope for 'magic' here is framed with reference to cycling between periods of anticipation and disappointment (Franklin 1997; Throsby 2004; Peddie, Teijlingen and Bhattacharya, 2005). 
Despite the challenges presented by infertility within the lives of posters, the use of humour to lighten the situation was evident in many posts, for example:

L'Arginine is an amino cause that helps blood flow. I don't know about its effect on sperm quality, but supplementing with it gives rock solid erections!;-) (P28M)

Other studies illustrate how humour is used as a way of managing threatening situations for men, notably where masculinity may be undermined (Verdonk, Seesing and de Riijk, 2010), such as in the context of infertility and perceptions around the 'fertility-virility linkage' (Lloyd, 1996).

These posts presented a construction of male fertility that is malleable or elastic, in that it contains properties which can be moulded or altered via lifestyle changes such as dietary modifications and exercise or through the use of supplements and vitamins. Commitment to vitamin and supplement regimes clearly conforms to medicalised constructions of (fertility) health and wellbeing, where specific substances and behaviours are invested with power and promise. These quests for fertility enhancements demonstrate the potentially fallible properties of male virility. Long-standing assumptions about sperm and male potency as features of virility and therefore reproductive masculinity are undermined in the light of discussions about the generative benefits of vitamin supplements for sperm.

\section{Fitness to father}

As detailed above, vitamins featured prominently in the generalised lifestyle advice offered and success stories shared alongside discussion about other lifestyle changes. Vitamins always came first, but posters acknowledged a raft of other lifestyle behaviours for modification when it came to improving their chances of conception:

My husband took the Wellman plus separate Vits $E$ and $C$ and zine, selenium and folic acid too. He also cut out drinking fully for the three months prior to our last cycle...We'll never 
know but I'm sure what my husband did make the difference as I did nothing different to what I'd done in our previous cycles (P3OF)

Sacrifice and extent of change was also emphasised and explicitly linked to the desired outcome, i.e. of becoming a father:

I've completely changed my lifestyle and an xmas without the usual treats will be strange BUT the stress/pressure from having this problem hanging over my head is well worth $110 \%$ effort (P7M)

Hubby has now turned mega healthy in preparation for his next test to see if it makes a difference (P11F)

The rationale for lifestyle modifications was made explicit by posters, such as their desire to ensure their reproductive organs were as healthy as possible. Some of the examples that men and women on the board provided around this, included the wearing of loose underwear or trousers and reducing cycling:

I am going to get changed into loose clothes every night after work (P4M)

Also reduced cycling 8-15 hours a week to 3-6 hours a week (P33M)

I lay off the cycling for a couple of weeks prior to having to provide my half of the equation at ET [Egg transfer] (P3M)

Thus notions which could historically be categorised as 'urban myth' (i.e. wearing tight underwear ${ }^{4}$ and cycling being bad for male fertility), were here being reported as tacit knowledge and as viable lifestyle improvements with which men could engage to improve their chances of conception. There appears to be some tension between here broader desires for men to be 'generally fit', such as

\footnotetext{
${ }^{4}$ The NICE guidance state that 'Men should be informed that there is an association between elevated scrotal temperature and reduced semen quality, but that it is uncertain whether wearing loose-fitting underwear improves fertility' (NICE, 2013: 9).
} 
through taking more exercise, and specific adaptations that relate to testicle and sperm health (such as not cycling), demonstrating perhaps the wider uncertainly around discourses of what being 'fertility fit' entails.

There were also some discussions around lifestyle and sex in relation to improving sperm function, for example:

It's very important to keep the testicles cool, wear loose underwear and let the air get to your nether regions. It's also important to 'clear the pipes' so to speak every couple of days to encourage fresh new sperm (P26F)

He went back for a second test and things improved minutely enough...on our last failed IVF attempt, the doctor reviewed out stats and unbelievably on the day he produced a normal sample...Only things that changed were that he had started taking the vitabiotics, wore looser comfy trousers and (I'm not joking) I'm guessing the porn in the ivf clinic was pretty good! (P27F)

Interestingly, the posts around sex or arousal came mostly from women (with the exception of one post about the benefit for erections of a supplement which was posted by a man). Perhaps men would feel uncomfortable discussing such aspects on forums, particularly when there were clearly a number of women posting actively on the men's board. Sex and arousal are often viewed as private and personal aspects of social life, and even within the context of infertility, presenting such issues may feel challenging. Although claims around links between porn and sperm quality do not appear in the medical discourses around fertility improvement, forum posters, by virtue of being part of the 'community of practice', offer a variety of narratives rooted in their lived experiences, and perhaps reflect hopefulness of infertile couples that some or all lifestyle factors may make the difference and thus help facilitate their often longed for conception. 
Other accommodations for male factor infertility (i.e. low sperm count, low morphology) were highlighted across the forum, with individual men often citing multiple practices:

I've got low morphology at $98 \%$ abnormal sperms so since our last cycle in March, l've been T-total and laid off the coffee totally...started weight training in the gym and I've been taking Proxeed too (P33M)

Often when posters described their lifestyle changes others were quick to reassure, again reinforcing lifestyle factors as valuable means for achieving 'success':

You're basically doing all the right things (P19F)

It seems to me like you are following a great diet and lifestyle. Well done! (P31F)

Such reassurance was often provided by women, despite the board being aimed at men, and the framing of women's posts was caring and supportive, often using terms of endearment and including kisses e.g. ' $x x^{\prime}$ at the end of posts. Male responses were more likely to detail their own regimes rather than congratulating others on theirs.

A number of the posters appeared to adhere to the position that sperm health could be improved, and that lifestyle factors such as poor diet, or being overweight were 'triggers' for fertility issues:

The consultant couldn't stress too much the negative impact of even moderate drinking and he[husband] exercised and lost about a stone in the months running up to it...everything suggests being overweight impacts your sperm quality massively (P30F)

Some men reported abstaining from poor health behaviours in their quest to seek further lifestyle advice:

I don't smoke, drink or do any of the stuff that causes these kind of problems (P18M) 
I have given up alcohol for 13 weeks now...I don't smoke and think I follow a pretty healthy diet...I do have one coffee a day, however I read that al caffeine should be cut out (P17M)

Overall, many men positioned themselves as health-conscious and committed to fertility health, resisting notions of masculinity which see men as passive within reproduction or their role and behaviours in this realm as secondary to those of women (Daniels, 2006). Whilst vitamins were valued as the key route to improved fertility health, and privileged above other lifestyle changes, men reported a range of accommodations, including avoiding tight underwear, reducing cycling, cutting down coffee, reducing smoking, giving up alcohol and taking the 'right' exercise and diet were highlighted on the forum. Posters seemed invested in the value of lifestyle, viewing it as part of 'project parent' and again seeing male fertility as something which could be amended and to which they should provide attention. Other work has suggested that men prefer active or pragmatic approaches to health problems (Poljski, Tasker, Andrews, Wijesinha, Piterman and de Kretser, 2003).

\section{Men's commitment to lifestyle change}

For forum contributors, lifestyle change implied careful planning and investment, with posters detailing their commitment to specific regimes:

I am going to continue working on losing the weight, but I have also put into place a couple of other plans as well (P4M)

I have given up alcohol for 13 weeks now...I don't smoke and think that I follow a pretty healthy diet. I run 2-3 times a week between $7-11 \mathrm{~km}$ each time and also do weight training. In terms of diet, I eat quite a bit of salmon, chicken and have cut out quite a lot of sugar. I do have one coffee a day (P17M)

Well its been 8 weeks since I started the whole get match fit and try and improve my chances...walking the dog further $\mathrm{n}$ further/exercise does seem to work, I've dropped a size 40-38...It's only been 8 weeks but scarily hopeful for improved results (P6M) 
A range of practices are implicated in such posts, with motivation and commitment signalled by details about time (e.g 8 weeks/13 weeks), frequency (e.g. 2-3 times a week), distance (e.g. 7-11km/further and further) and quantified loss (e.g. size 40-38). However, gendered discourses questioning commitment could also be found within the lifestyle posts. Despite it being a men's board, some female contributors used the space to signal a lack of commitment from their male partners, in contrast to a female readiness to 'do anything' required to achieve conception: "I'm ready to do anything we need to do to improve our chances" (P2F). Some women used the board to seek advice about commitment in relation to perceived men's issues, such as alcohol consumption:

Can any men or ladies offer some advice on TTC and drinking alcohol?...Me and DH [Darling husband] have always had an on-going battle about booze...it's reached the point when I literally shudder when I hear a can of beer being opened. He drinks over the recommended weekly allowance....but I feel that with our circumstance he needs to be more committed and I feel like I'm forever waiting for the day when he takes it seriously...I feel as though I don't want to go into another treatment cycle without giving it $100 \%$, from both of us- which is what I have been doing in terms of diet, drinking, alternative therapies etc etc (P1F)

The importance of lifestyle change in the above post is tied to context ('our circumstance'), requiring dedication ('takes it seriously'; giving it 100\%') and action across many fronts ('diet, drinking, alternative therapies etc. etc.'). Hegemonic forms of masculinity in this context may therefore become about being in control of your own fertility health and working hard on it, again challenging notions of men as passive in reproduction (Daniels, 2006). The man's lack of commitment is signalled via excessive alcohol consumption and time elapsed without action ('forever waiting'), while the woman positions herself as active and open-minded.

This original post generated further supportive posts, mostly from other: 
It winds me up massively when men will not do something simple like give up drinking when we have to go through so, so much. Given that you have already been through ICSI [Intracytoplasmic sperm injection], it is unfathomable that he would persist knowing that you have to undergo invasive, humiliating procedures all so he can have a drink...I just can't understand the mentality of some men $:(\mathrm{P} 14 \mathrm{~F})$

This post makes a more general claim about male-female differences with respect to commitment towards reproduction. The relatively minimal ('simple') obligations of men regarding lifestyle modifications are contrasted with the all-encompassing changes endured by women ('so, so much'), then reinforced by the overwhelming embodied experience of fertility treatment by the original contributor. The male-female differences are further highlighted through recourse to the idea of the 'mentality of some men', which is presented as unfathomable to the women poster.

The original poster then underlines her partner's irresponsibility by referencing another husband's commitment and subsequent success:

I have a friend who has the same issues as us but her hubby has completely given up booze and their first IVF worked for them- and their test date was the same time as our last treatment and I'm struggling to come to terms with it- I wish it was my hubby that gave up booze and wish our treatment worked first time (P1F)

Giving up alcohol and successful IVF are here conflated by the poster, apportioning blame to the male partner, and further reinforcing notions of why commitment to lifestyle change is seemingly so important, as is seen in other health narratives (such as whether smokers and those or are obese should have access to NHS health care for example). Reluctance by some men to alter practices such as drinking led some women to extend commitment further, into questioning their fitness to be fathers at all and highlighting debates around what 'good' parenthood entails: 
If he's going to be a father, he needs to face what is really bothering him (i.e. the reason he drinks in the first place and cant give up) (P14F)

If you manage to have a child he will have to cut down anything so he might as start now (P15F)

Such critiques of 'fitness to father' were primarily from women, although one man offered a defence of men in this context, in doing so highlighting that no other men had replied to this thread:

As no other guys have posted yet I thought I may as well. Drink has been a sore subject with me and my $\mathrm{OH}$ too- the discussion first came up when we'd been trying to conceive naturally for a year. She wanted me to cut down to the advised limits, which lets be honest is fair enough. Now I'm not a massive drinker, but this wound me up. I KNEW she was right, but I hated having to watch what I was drinking all of the time (P34M).

Poster 34 (Male) went on to discuss being 'nagged' by women around alcohol consumption and the challenge of infertility to men's sense of self. Alcohol was also presented as a means of coping with emotional pain; functions neglected by women posters. The degree of commitment to lifestyle changes relevant for fertility and health was thus construed in powerful moral terms: men who did not engage were perceived by women to be irresponsible partners whose suitability for fathering was compromised. Earlier discourses of reproductive masculinity and their intersection with ideals of normative fatherhood positioned men as distant from the health of their offspring. In the accounts in the present study, we instead see the appearance of moral discourses centred around fitness and men's capacity as effective fathers.

\section{Discussion}

The analysis presented here demonstrates how lifestyle changes to get 'match fit' for conception, were accepted by both male and female posters as a dyadic route to reproductive success. Male fertility was presented as something malleable and thus behaviour change was constructed as a means 
by which fertility could be improved. These narratives suggest a shift in the conceptualisation of male fertility as resistant to vulnerability and harm, a position which challenges earlier constructions of reproductive masculinity (Daniels, 2006) and which also materialises via current anxieties around declining sperm counts. Help-seeking and help-giving were highly visible and forums do offer the potential for posters to come together and share information and knowledge gathered from their own lived experiences (Hanna and Gough 2016b) and can, as the forum examined here demonstrates, be a space in which talk about lifestyle changes can occur and where men can exhibit their own reproductive commitment.

Vitamins were a highly dominant feature of lifestyle advice and information posts on the forum with broader lifestyle factors appearing, albeit, less frequently compared to discussions about vitamins. In the context of infertility where couples are highly motivated to achieve conception, vitamins seem to be imbued with much hope and expectation ('scarily hopeful' P6M), narrated as being almost magical in their (potential) properties. Yet vitamins are products marketed by pharmaceutical companies with no obvious certainty about their value or effectiveness (Ebrahimjee, Dahl and Eagle, 2015).

The dominant focus on vitamins appears to support notions that health and lifestyle domains and practices are increasingly consumer-orientated (Lewis, 2006), withvitamins and supplements presented as purchasable solutions. The discourse that some on the forum presented around vitamins as a 'quick fix' appears then to fit with wider social narratives around drugs and supplementation as a way of 'solving' issues within an increasingly medicalised contemporary society (Conrad and Leiter, 2004, Clarke et al. 2003). This extends the position that biomedicine is a solution to fertility and conception difficulties and that infertility is a disease (Becker and Nachtigall 1992, Barnes, 2014; Conrad and Lieter, 2004; Greil, 2002). Correspondingly, an inability to conceive is discussed in terms of 'treatment' and 'clinics', which roots it firmly in the biomedical, with commodified and individualised solutions increasingly accepted. 
As society becomes increasingly medicalised, a growing use of lifestyle commodities such as health supplements or vitamins are utilised by individuals to try to 'resolve' the issues they are facing. There is also a burgeoning social narrative, which is apparent in the talk about lifestyle on this forum, that individual health is just that, individual; being healthy is now about improving your own health through working on your own 'body project' (Kerr, 2013), further reinforcing notions of healthism. While discourses around women's responsibilities towards the health of their unborn offspring are already embedded and evident (c.f. Lee, 2014, Waggoner 2017), our data suggest that lifestyle management and fertility accountability and pre-conception care may be seen as matters for men as future parents too; an idea which runs counter to assumptions about men as removed from practices of health, fertility and conception (Daniels, 2006)

Although the forum board examined was aimed at men specifically, women were regular contributors, including starting and replying to threads. Notably, women would provide 'knowledge' to male posters on particular topics, often reporting their partner's experiences or outcomes as supporting evidence for their posts. Other research has suggested that women may have greater awareness of lifestyle factors in relation to infertility (Hawkins et al 2014), and that women may be 'prescribers' of lifestyle regimes to their male partners (Porter and Bhattacharya, 2008). Men can, however, claim agency in enacting lifestyle changes, and given that men themselves were seeking help and support this offers some evidence of male engagement in the reproductive realm. Some female posters presented men's commitment as less than theirs in relation to 'enduring' fertility treatment. Other authors have suggested that women may view infertility as a 'second job' (Steuber and Soloman, 2008; 844), demonstrating the strength of commitment women may present around the 'reproductive project'. Gendered differences around the reproductive body project - directly analysed via a comparison of the lifestyle changes of men and women - would help to further understand these processes and their relationship to reproductive masculinity. 
As demonstrated in this paper, men described their commitment to engaging in lifestyle behaviour change, often directly connected to ideas around improving their sperm. Lifestyle practices could therefore be a means for men to manage or deal with infertility, allowing them to engage in some active processes in what is otherwise seen as a disempowering, disembodied or potentially emasculating experience for men (Hanna and Gough, 2016a and b). As other work has suggested, infertility is a source of powerlessness (Hanna and Gough, 2017), and lifestyle modifications are an aspect which individuals may feel they have control over (Porter and Bhattacharya, 2008), which may help to understand posters' preoccupations with getting lifestyle 'right'. Lifestyle may be a means through which men can have a sense of embodied reproductive agency (Ameling and Waggoner, 2013) and in displaying such agency men may implicitly demonstrate a more engaged or emergent form of reproductive masculinity (Inhorn 2012, Hanna and Gough, 2017; Hudson and Culley, 2013). There were also underpinning ideological and moral assumptions present in the posts relating to what being a 'good father' entails, and which link to broader discourses around parenting cultures (Lee, Bristow, Faircloth and Macvarish, 2014) and how this is constructed in relation to health and lifestyle practices. Being committed to achieving conception appeared to be viewed as requiring a 'regime' for health, reinforcing individual healthism, although such regimes often appeared as punishing for men (despite them narrating it as 'worth it').

\section{Conclusion}

Online discussion forums can provide a window into understanding the ways in which men (and women) mediate the complex and distressing life event of infertility through a focus on lifestyle. In these accounts, male fertility is presented as malleable and as a means via which men's agency in the context of infertility can be realised. Lifestyle adaptations can therefore become a means by which men may actively enact a more positive and engaged version of reproductive masculinity in an otherwise disempowering context. 
Whilst acknowledging that the research is based on one online forum only, this paper provides a starting point which suggests that lifestyle factors and accommodations for conception are being employed within contemporary procreation narratives. People are actively engaged in responding to wider health messages which locate the individual and/or couple as responsible for their fertility successes and failures. Powerful discourses of lifestyle, individualisation and healthism increasingly appear to frame and position infertility experiences as part of an individual's embodied lifestyle project. Doing 'lifestyle work' may therefore become an important part of attempting to achieve conception. 'Fitness to father' takes on a linked meaning here; being 'fit' in terms of reproductive health is viewed as positive for achieving conception and is a means to demonstrate men's commitment to the dyadic goal of parenthood. These fertility practices allow for the articulation of a revised form of reproductive masculinity, which sees men as engaged reproductive actors, their virility as vulnerable to harm and not guaranteed, and their role as significant in the health of their future children. In exploring these lifestyle specific aspects of men's reproductive experiences, this paper therefore advances that ideas around reproductive masculinity may be shifting within contemporary society.

More research is however needed to explore how lifestyle changes may differ in other infertility contexts (both on and off line), for example examining other forums and exploring how men may describe and discuss lifestyle work offline. The issues pertaining to women posting in 'male spaces' also requires further consideration, particularly in relation to the elaboration of and challenges to reproductive masculinity. The relationship between discourses of male fertility improvement and the commodification of fertility treatment more generally also provide important avenues for expanding understandings of lifestyle and infertility. Understanding how broader societal shifts towards individualistic and medicalised practices impact on the experience of infertility, particularly around the potential stresses which lifestyle modification for in/fertility could bring, are therefore urgently needed. 


\section{References}

Anderson, K, Nisenblat, V and Norman, R. (2010). Lifestyle factors in people seeking infertility treatment- A review. Australian and New Zealand Journal of Obstetrics and Gynaecology. 50: 8-20 Almeling, R, and Waggoner, M.R. (2013). More and less than equal how men factor in the reproductive equation. Gender \& Society, Doi: 0891243213484510.

Ausmees, K, Mandar, R, Korrovits, P, Zarkovski, M, Timberg, G and Punab, M. (2012). Reproductive function in middle-aged males: healthy men versus male partners of infertile couples. Andrologia. 46: $118-125$

Axelsson, J, Bonde, J, Giwercman, Y, Rylander, L and Giwercman, A. (2010). Gene-environment interaction and male reproductive function. Asian journal of Andrology. 12: 298-307

Barnes L. (2014). Conceiving Masculinity: Male Infertility, Medicine, and Identity. Philadelphia, PA: Temple University Press

Braun, V. and Clarke, V. (2006). Using thematic analysis in psychology. Qualitative research in psychology 3(2): 77-101.

Clarke, A. Mamo, L. Fishman, J. Shim, J. Fosket, J. (2003) Biomedicalization: Technoscientific Transformations of Health, Illness, and U.S. Biomedicine. American Sociological Review, 68: 161-194 Conrad, P and Leiter, V. (2004). Medicalization, Markets and Consumers. Journal of health and social behaviour. 45: 158-176

Crawford, R. (1980). Healthism and the medicalization of everyday life. International journal of health services. 10(3): 365-388. 
Daniels, C. (2006). Exposing Men: The science and politics of male reproduction. New York: Oxford University Press

Dent, M. (2006). Patient choice and medicine in health care: Responsibilization, governance and proto-professionalization. Public Management Review. 8(3): 449-462.

Ebrahimjee, M., Dahl, S. and Eagle, L. (2015). Lifestyle, Health and Pharmaceutical Marketing. Marketing Ethics \& Society: 189.

Fertility Weekly. (2015). Semen quality; Lifestyle factors are involved. January 2015: 3

Franklin, S. (1997). Embodied Progress: A Cultural Account of Assisted Conception. London: Routledge.

Gaur, D, Talekar, M and Pathak, V. (2010). Alcohol intake and cigarette smoking: Impact of two major lifestyle factors on male fertility. Indian Journal of Pathology and Microbiology. 53 (1): 35-40 Greil, A.L., (2002). Infertile bodies: Medicalization, metaphor, and agency. In Inhorn, M.C. and Van Balen, $\mathrm{F}$ (Eds). (2002). Infertility around the globe: New thinking on childlessness, gender, and reproductive technologies. Berkeley: University of California Press: 101-118.

Hanna, E. and Gough, B. (2016a). Emoting infertility online: A qualitative analysis of men's forum posts. Health:, 20(4): 363-382.

Hanna, E. and Gough, B. (2016b). Searching for help online: An analysis of peer-to-peer posts on a male-only infertility forum. Journal of health psychology. doi: p.1359105316644038.

Hanna, E. and Gough, B. (2017). Men's accounts of infertility within their intimate partner relationships: an analysis of online forum discussions. Journal of Reproductive and Infant Psychology, 35(2): 150-158. 
Hawkins, L, Rossi, B, Correia, K, Lipskind, S, Hornstein, M and Missmer, S. (2014). Perceptions among infertile couples of lifestyle behaviours and in vitro fertilization (IVF) success. J Assis Reprod Genet. 31: $225-260$

Hudson, N. and Culley, L. (2013). 'The bloke can be a bit hazy about what's going on': men and crossborder reproductive treatment. Reproductive biomedicine online, 27(3): 253-260.

Inhorn, M.C. (2012). The new Arab man: Emergent masculinities, technologies, and Islam in the Middle East. Princeton University Press.

Jurewicz, J, Radwan, M, Sobala, W, Ligocka, D, Radwan, P, Bochenek, M and Hanke, W. (2015). Lifestyle and semen quality: role of modifiable risk factors. Systems Biology in Reproductive Medicine. 60 (1): $43-51$

Karavalos, S, Stewart, J, Evbuomwan, I, McEleny, K and Aird, I. (2013). Assessment of the infertile male. The obstetrician and Gynaecologist. 15:1-9

Kerr, A. (2013). Body work in assisted conception: exploring public and private settings. Sociology of health \& illness. 35(3): 465-478.

Lee, E. (2014). Policing pregnancy: The pregnant woman who drinks. In Lee, E., Bristow, J., Faircloth, C. and Macvarish, J., 2014. Parenting culture studies. Basingstoke: Palgrave Macmillan: 129-146

Lewis, T. (2006). Seeking health information on the internet: lifestyle choice or bad attack of cyberchondria. Media, Culture and Society. 28 (4): 521-539

Lloyd, M. (1996). Condemned to be meaningful: Non-response in studies of men and infertility. Sociology of Health \& IIIness. 18(4): 433-454.

Lohan, M. (2015). Advancing research on men and reproduction. International Journal of men's health. 14 (3): 214-232 
National Institute for Health and Care Excellence. (2013). 'Fertility problems: Assessment and treatment'. Clinical guidance 156. NICE

Nouri, K, Huber, D, Walch, K, Promberger, R, Buerkle, B, Ott, J and Tempfer, C. (2014). Fertility awareness among medical and non-medical students: A case-control study. Reproductive biology and endocrinology. 12: 94

Paetchter C. (2003). Masculinities and feminities as communities of practice. Women's Studies International Forum 26(1): 69-77.

Peddie, V.L., Van Teijlingen, E. and Bhattacharya, S. (2005). A qualitative study of women's decisionmaking at the end of IVF treatment. Human Reproduction. 20(7): 1944-1951.

Poljski, C, Tasker, C, Andrews, C, Wijesinha, S, Piterman, I and de Kretser, D. (2003). GP attitude to male reproductive and sexual health education and promotion. Australian Family Physician. 32 (6): 462- 465

Porter, M and Bhattacharya, S. (2008). Helping themselves to get pregnant: a qualitative longitudinal study on the information-seeking behaviour of infertile couples. Human Reproduction. 23 (3): 567572

Povey, A and Stocks, S. (2010). Epidemiology and trends in male subfertility. Human Fertility. 13 (4): $182-188$

Rato, L, Alves, M, Cavaco, J and Oliveria, P. (2014). High-energy diets: a threat for male fertility? Obesity Reviews. 15: 996-1007

Sharpe, R.M. (2000). Lifestyle and environmental contribution to male infertility. British medical bulletin. 56(3): 630-642. 
Sher, J. (2016). Prepared for pregnancy? Pre-conception health, education and care in Scotland. Report for NHS Greater Glasgow and Clyde. [Online]. Available at: http://cdn.basw.co.uk/upload/basw 65049-1.pdf Accessed 3/1/17

Spar, D. (2006). The baby business: How money, science and politics drive the commerce of conception. Boston: Harvard Business School Press

Steuber K and Solomon D. (2008) .Relational uncertainty, partner interference, and infertility: A qualitative study of discourse within online forums. Journal of Social and Personal Relationships 25(5): 831-855.

Stommel W and Koole T (2010). The online support group as a community: A micro-analysis of the interaction with a new member. Discourse Studies 12(3): 357-378.

Throsby, K. (2002). Negotiating "normality" when IVF fails. Narrative Inquiry. 12(1): 43-65.

Verdonk, P., Seesing, H. and de Rijk, A., (2010). Doing masculinity, not doing health? A qualitative study among Dutch male employees about health beliefs and workplace physical activity. BMC public health, 10(1): 712.

Waggoner, M., 2017. The Zero Trimester: Pre-Pregnancy Care and the Politics of Reproductive Risk. Univ of California Press.

Williams, M. (2000). Interpretivism and generalisation. Sociology. 34(2): 209-224.

Wright, C, Milne, S and Leeson, H. (2014). Sperm DNA damage caused by oxidative stress: modifiable clinical, lifestyle and nutritional factors in male infertility. Reproductive Biomedicine Online. 28: 684703 
Zilberlicht, A, Wiener-Megnazi, Z, Sheinfield, Y, Grach, B, Lahav-Baratz, S and Dirnfeld, M. (2015).

Habits of cell phone usage and sperm quality- does it warrant attention? Reproductive BioMedicine Online. 31: 421- 426 